\title{
OPTIMALISASI PERAN PEREMPUAN BERBASIS MODAL SOSIAL PADA SEKTOR PEMERINTAHAN DESA (Study pada Pengelolaan Dana Desa)
}

\author{
Titi Darmi
}

Received Article: 4 Agustus 2016

Accepted Article: 10 November 2016

\begin{abstract}
The third Nawa Cita of Presiden Jokowi is build Indonesia on the outskirts, it is meaningful that national development focused on villages oriented throughout Indonesia, so that Indonesian villages become self-sufficient village and competitiveness. Nawa cita is an orientation of the national development planning 2015 -2019. The government has budgeted rural development on average earn 800 - $1 M$ rupiahs for every village in accordance with the Act mandates. Based on the findings of the Coruption Eradication Commission of RI occur irregularities in the management of the Village Fund (Dana Desa/DD), including the use of DD does not correspond to the needs of the community. DD management principle is transparent and acomodate public participation, however it has not been made by manager DD. Women's participation and transparency for the public should be rise the public trust in the village officials in managing the funds of the village, however it never been taken. Role of women in planning the work program of the village called APBDes, can filter aspirations in accordance with the needs of society based on values, norms and culture. By optimizing the women role can capture the aspirations of society and openness in the management of the fund that all can be used as social capital village to village governance in the management of DD. Social capital will make the villagers and village officials have a strong bond, mutual trust, to avoid a conflict so as a valuable capital to build and boost the economy in the village.
\end{abstract}

Keywords : woman's role, social capital, village fund (Dana Desa/DD) management.

\section{Abstrak}

Nawa Cita ketiga Presiden Jokowi tentang membangun Indonesia dimulai dari pinggiran, hal tersebut bermakna bahwa pembangunan nasional difokuskan kepada pembangunan desa-desa. Nawa cita sebagai sebuah orientasi sasaran pembangunan yang strategis dalam RPJMN tahun 2015-2019 yang mengamanatkan sasaran pembanguan desa dengan cara meningkatkan jumlah desa mandiri. Pemerintah memiliki anggaran pembangunan desa rata-rata antara 800 juta sampai 1 milyar rupiah setiap 1 desa berdasarkan kepada amanat Undang-Undang. Berdasarkan kepada temuan KPK RI bahwa banyak ditemukan permasalahan pengelolaan Dana Desa, yaitu: penggunaan Dana Desa tidak sesuai dengan kebutuhan masyarakat. Pengelolaan Dana Desa secara prinsipnya adalah terbuka dan mengakomodasi semua partisipasi masyarakat, akan tetapi dalam pelaksanaannya tidak dilaksanakan oleh pengelola dana desa tersebut. Partisipasi perempuan dan keterbukaan kepada masyarakat seharusnya menjadi suatu kepercayaan masyarakat terhadap pengelola dana desa akan tetapi tidak pernah terjadi. Peranan para perempuan dalam merencanakan pelaksanaan program-program desa yang disebut dengan APBDesa, dapat menampung aspirasi-aspirasi mereka melalui kebutuhan masyarakat berdasarkan nilainilai, norma dan budaya. Melalui optimisasi peranan perempuan dapat melibatkan aspirasi-aspirasi masyarakat dan keterbukaan pengelolaan dana desa yang kesemuanya dapat digunakan sebagai kapital sosial desa menuju pemerintahan yang bersih dalam pengelolaan Dana Desa. Kapital sosial menjadikan warga desa dan pemerintah desa kuat dan memiliki kepercayaan bersama untuk menghindari konflik sehingga sebagai sebuah kesatuan untuk membangun perekonomian desa tersebut.

Kata kunci: peranan perempuan, kapital sosial, Pengelolaan Dana Desa

\footnotetext{
${ }^{1}$ Penulis adalah Dosen tetap Administrasi Publik FISIP Universitas Muhammadiyah Bengkulu 


\section{A. Pendahuluan}

stilah "Tikus mati di lubung padi" dan pembangunan desa yang terlupakan, tidak akan terjadi dengan terbitnya Undang - Undang (UU) Desa, merupakan kebijakan kijaksana pemerintah Pusat dalam rangka meningkatkan kesejahteraan ma syarakat Desa, meningkatkan kualitas hidup masyarakat desa, penanggulangan kemis kinan melalui penyediaan pemenuhan kebutuhan dasar, pembangunan sarana dan prasarana, pengembangan potensi ekonomi lokal, serta pemanfaatan sumber daya alam dan lingkungan secara berkelanjutan, sehingga desa (masyarakat) memiliki daya saing. Hal ini, sejalan dengan Visi Misi Nawacita Presiden Jokowi bahwa mem bangun Indonesia dimulai dari pinggiran dengan memperkuat daaerah-daerah dan desa dalam kerangka negara kesatuan. Itu artinya, pembangunan pedesaan tujuan utama pembangunan Nasional karena memiliki sasaran yang strategis dalam RPJMN tahun 2015-2019 yang menga manatkan sasaran pembanguan desa dengan cara meningkatkan jumlah desa mandiri ${ }^{1}$.

Komitmen untuk menerapkan UU tersebut, ditunjukkan pemerintah pusat dengan mengalokasikan anggaran dana desa yang cukup besar, tercatat pada tahun 2015 dana desa dialokasikan dan terealisasi sebesar 20,76 triliyun dan pada tahun 2016 ini, pemerintah Pusat mengalokasikan dana desa sebesar 46,98 triliyun, diperuntukan lebih kurang 74.093 desa, kalaulah dibagi rata per desa, desa akan mendapat anggaran lebih kurang 600 juta rupiah sampai 800 juta rupiah setiap desa $^{2}$. Dalam pengalokasian besarnya dana desa yang diterima setiap desa berdasarkan indikator jumlah penduduk, luas wilayah, tingkat kemiskinan, dan tingkat kesulitan geografis. Dana desa tersebut diprioritaskan untuk pembangunan dan pemberdayaan masyarakat sesuai dengan kesepakatan masyarakat desa tertuang dalam RPJMDes, RKPDes dan APBDes. Kebijakan pengalokasian Dana Desa (DD) sebetulnya memiliki potensi luar biasa dalam upaya mempercepat pertumbuhan dan pembangunan desa dalam rangka mengatasi berbagai persoalan yang selama ini, yang membuat desa menjadi bagian wilayah yang selalu terpinggirkan. Desa kemudian identik dengan keterbelakangan, kapasitas sumberdaya manusia yang rendah, penduduk usia renta. Dengan adanya pengalokasian DD merupakan harapan masyarakat desa, sebagai bantuan stimulan atau dana perangsang untuk mendorong dalam membiayai program Pemerintah Desa yang tertuang dalam APBDes.

Berdasarkan kajian Komisi Pem berantasan Korupsi (KPK) banyak ditemukan permasalahan pengelolaan DD, yaitu: 1) UU Desa dan regulasi pendukung belum sepunuhnya dipahami oleh stakeholder; 2) masih tingginya potensi korupsi di daerah; 3) desa relatif mudah dimanfaatkan untuk mendapatkan kantung suara pada saat pilkada dan pemilu; 4) partisipasi, akuntabilitas dan transparansi masih rendah ${ }^{3}$. Masih kurang maksimal partisipasi swadaya gotong royong masyarakat ${ }^{4}$. Artinya rendahnya partisipasi masyarakat dalam kegiatan-kegiatan yang dibiayai Alokasi Dana Desa (ADD) juga menunjukkan kurangnya keterlibatan masya rakat dan kurang komunikasi dari pemerintahan desa kepada masyarakatnya. Padahal, amanat UU mengatakan bahwa penggunaan dana desa dalam menentukan program pembangunan kerja desa berda sarkan partisipasi masyarakat, artinya masyarakat dilibatkan terutama kaum perempuan dalam membuat program kerja, agar program kerja yang ditetapkan dalam APBDes sesuai dengan kebutuhan masya rakat desa. Pengelolaan dana desa didasarkan dengan partisipasi masyarakat dipercaya akan menimbulkan rasa memiliki. Keikutsertaan masyarakat di dalam setiap tahapan perencanaan pembangunan desa, dengan menggunakan anggaran dana desa, sebagai upaya menumbuhkan rasa memiliki ("sense of ownership" atau "sense of belonging"), rasa memiliki bagian dari unsur modal sosial, terhadap sarana atau prasarana yang dibangun. Dengan adanya rasa memiliki ini pada gilirannya akan menghasilkan pembangunan yang berke lanjutan (sustainability).

Masih ada paradigma sebagian masyarakat dan pemerintah, yang belum menyadari bahwa ada ketimpangan relasi Gender yang berbasis kekuasaan yang berlangsung sekarang ini. Di lihat dari kesenjangan status pekerjaan utama. Persentase perempuan sebagai pekerja 
keluarga mencapai hampir 29 persen dari semua perempuan usia 15 tahun ke atas yang bekerja. Angka tersebut jauh lebih tinggi dari persentase laki-laki yang hanya 6 persen. Hal ini menunjukkan persentase perempuan yang bekerja namun tidak men dapat upah jauh lebih tinggi dibandingkan laki-laki ${ }^{5}$. Hal ini berdampak pada semakin kecilnya peran dan fungsi perempuan dalam pelaksanaan pembangunan sehingga kua litas hidup perempuan tidak menjadi lebih baik dan jumlah perempuan miskin semakin bertambah. Berdasarkan data Badan Pusat Statistik (BPS) Indonesia di Lingkungan Asean Indeks Pembangunan Gender (IPG) masuk katagori rendah menduduki peringkat ke 3 terbawah dari negara-negara Asean. Padahal, potensi jumlah penduduk perem puan usia subur pada tahun 2014 sebesar lebih dari 60 juta, atau lebih dari 50 persen jumlah penduduk perempuan. Jumlah penduduk perempuan pada kelompok usia 15 - 16 tahun, mencapai 85 juta, atau sekitar 67 persen dari penduduk perem puan. Jumlah yang besar ini menunjukkan potensi sumber daya manusia untuk pembangunan. Jika perempuan tidak mam pu berkarya secara produktif, maka akan menjadi beban ekonomi bagi bangsa Indonesia ${ }^{5}$.

Dalam rangka pembangunan Indo nesia secara umum, Desa khususnya, pada prinsipnya harus memberikan keadilan dan kemakmuran kepada semua masyarakat, kepada laki-laki maupun perempuan, kepada yang kaya maupun yang miskin, tanpa membedakan status sosial untuk melaksanakan sesuai perannya. Terutama perempuan dapat berperan dan ikut serta dalam merencanakan pembangunan desa dengan mengunakan anggaran dana desa. Salah satu pendekatan yang tepat adalah pemerintahan Desa melakukan transparansi dan mengikutsertakan perempuan setiap tahapan perencanaan pembangunan. $\mathrm{Pe}$ nulis melihat masih ada gap dan belum ada kesetaraan peran, keterlibatan perempuan dalam pengelolaan dana desa. Banyak kajian yang menyatakan pentingnya modal sosial ${ }^{6,7,8,9}$ dan ${ }^{10}$ agar kesetaraan peran antara laki-laki dan perempuan dapat terwujud, akan timbul rasa memiliki, rasa percaya antara masyarakat dengan pengelola dana desa sesuai dengan norma, nilai dan budaya sosial masyarakat setem pat.

Sementara penelitian yang membahas pentingnya keterlibatan masya rakat dalam pengelolaan sumberdaya di Pedesaan akan memiliki kontribusi yang signifikan terhadap suksesnya program yaang telah ditentukan ${ }^{11},{ }^{12},{ }^{13},{ }^{14},{ }^{15}$ dan $^{12}$ optimalisasi peran perempuan menjadi so lusi agar dalam merencanakan pengelolaan dana desa untuk pembangunan dapat berjalan maksimal, sehingga mandat UU Desa dan Nawa Cita ke tiga Presiden RI dapat terwujud dengan menjadikan desadesa mandiri dan memiliki daya saing.

\section{B. Peran Perempuan di Sektor Peme rintahan Desa}

etiap pembangunan seyogyanya melibatkan kaum perempuan sesuai dengan Instruksi Presiden Nomor 9 Tahun 2000 tentang Pengarusutamaan Gender (PUG) dalam Pembangunan Nasional. Program kesetaraan dan keadilan gender ini tercantum sebagai salah satu strategi untuk mengoptimalisasi peran perempuan Indonesia. Implementasi PUG disampaikan kepada Departemen maupun Lembaga Pemerintah dan non Departemen serta Pemerintah Daerah (Pemda) seluruh Indonesia, untuk menjalankan pengusunan program dalam perencanaan, pelaksanaan, pemantauan dan evaluasi dengan memper timbangkan permasalahan kebutuhan, aspirasi perempuaan pada pembangunan dalam kebijakan, program/proyek dan kegiatan. Berdasarkan instruksi Presiden tersebut selayaknya, kiprah perempuan dalam setiap perencanaan pembuatan program pembangunan desa dengan alokasi Dana Desa dapat menjadi pedoman bagi setiap Pemerintahan Desa untuk melibatkan para perempuan.

Berdasarkan data BPS ${ }^{16}$ keterli batan perempuan di sektor Pemerintahan Desa di lihat dari kesetaraan Gender sangat rendah, dari 78.736 kuota Kepala Desa hanya 4.485 orang Kepala Desa nerjenis kelamin perempuan atau kiprah perempuan hanya $5,70 \%$, sementara untuk Sekretaris Desa dari 70.780 kuota, Sekretaris Desa dari perempuan hanya 7.156 orang atau lebih kurang 10,1\%, (baca tabel 1). Ini artinya peran perempuan di sektor Pemerintahan Desa masih sangat rendah, 
walaupun perempuan diberikan porsi $30 \%$ sesuai perundang-undangan, sangat disa yangkan peluang tersebut belum diambil oleh kaum perempuan. Rendahnya kese taraan Gender disebabkan beberapa faktor diantaranya karena faktor sosial, budaya dan tradisi yang dianut oleh warga desa serta kebijakan, regulasi dan program kerja belum konsen terhadap gender. Isu bahwa kaum perempuan berpartisipasi dalam urusan rumah tangga sedangkan dalam hal isu-isu sosial kemasyarakatan menjadi persoalan kaum pria. Sehingga berimplikasi pada kurangnya kiprah perempuan baik keterli batan perempuan untuk jabatan di pemerintahan Desa maupun keterlibatan dalam proses dan pelaksanan pembangunan Desa.

Tabel 1. Jumlah Kepala Desa Menurut Jenis Kelamin Tahun 2014

\begin{tabular}{|c|c|c|c|c|c|c|}
\hline \multirow{2}{*}{$\begin{array}{l}\text { Provinsi } \\
\text { Laki-Laki }\end{array}$} & \multicolumn{2}{|l|}{ Kepala Desa } & \multirow{2}{*}{ Jumlah } & \multicolumn{2}{|c|}{ Sekretaris Desa } & Jumlah \\
\hline & Perempuan & & & Laki-Laki & Perempuan & \\
\hline$(1) \quad(2)$ & $\frac{(3)}{3}$ & & (4) & $(\dot{5})$ & (6) & (7) \\
\hline Aceh & 6212 & 32 & 6244 & 5456 & 101 & 5557 \\
\hline Sumatera Utara & 5458 & 319 & 5777 & 4640 & 971 & 5611 \\
\hline Sumatera Barat & 1045 & 66 & 1111 & 688 & 317 & 1005 \\
\hline Riau & 1635 & 43 & 1678 & 1524 & 124 & 1648 \\
\hline Jambi & 1467 & 47 & 1514 & 1260 & 92 & 1352 \\
\hline Sumatera Selatan & 2854 & 182 & 3036 & 2541 & 309 & 2850 \\
\hline Bengkulu & 1413 & 69 & 1482 & 1274 & 130 & 1404 \\
\hline Lampung & 2422 & 142 & 2564 & 2098 & 131 & 2229 \\
\hline Bangka Belitung & 338 & 19 & 357 & 235 & 80 & 315 \\
\hline Kepulauan Riau & 372 & 24 & 396 & 224 & 37 & 261 \\
\hline DKI Jakarta & 207 & 60 & 267 & & 56 & 260 \\
\hline Jawa Barat & 5390 & 367 & 5757 & 4753 & 382 & 5135 \\
\hline Jawa Tengah & 7604 & 703 & 8307 & 5951 & 781 & 6732 \\
\hline DI Yogyakarta & 376 & 36 & 412 & 331 & 56 & 387 \\
\hline Jawa Timur & 7343 & 780 & 8123 & 6011 & 572 & 6583 \\
\hline Banten & 1221 & 57 & 1278 & 1416 & 83 & 1499 \\
\hline Bali & 671 & 14 & 685 & 623 & 60 & 683 \\
\hline NTB & 1117 & 14 & 1131 & 966 & 37 & 1003 \\
\hline NTT & 2975 & 127 & 3102 & 2342 & 242 & 2584 \\
\hline Kalimantan Barat & 1976 & 62 & 2038 & 1578 & 152 & 1730 \\
\hline Kalimantan Tengah & 1452 & 71 & 1523 & 1287 & 108 & 1395 \\
\hline Kalimantan Selatan & 1894 & 70 & 1964 & 1485 & 134 & 1619 \\
\hline Kalimantan Timur & 952 & 39 & 991 & 808 & 110 & 918 \\
\hline Kalimantan Utara & 457 & 12 & 469 & 413 & 29 & 442 \\
\hline Sulawesi Utara & 1511 & 313 & 1824 & 1283 & 416 & 1699 \\
\hline Sulawesi Tengah & 1835 & 84 & 1919 & 1718 & 151 & 1869 \\
\hline Sulawesi Selatan & 2687 & 307 & 2994 & 2012 & 598 & 2610 \\
\hline Sulawesi Tenggara & 1898 & 149 & 2047 & 1793 & 262 & 2055 \\
\hline Gorontalo & 629 & 86 & 715 & 356 & 273 & 629 \\
\hline Sulawesi Barat & 609 & 17 & 626 & 510 & 59 & 569 \\
\hline Maluku & 842 & 39 & 881 & 906 & 71 & 977 \\
\hline Maluku Utara & 1131 & 34 & 1165 & 1012 & 85 & 1097 \\
\hline Papua Barat & 1517 & 26 & 1543 & 1405 & 68 & 1473 \\
\hline Papua & 4741 & 75 & 4816 & 4521 & 79 & 4600 \\
\hline Indonesia & 74251 & 4485 & 78736 & 63624 & 7156 & 70780 \\
\hline
\end{tabular}


Isu tersebut terkonfirmasi dengan kondisi perempuan pedesaan Indonesia pada umumnya masih termarginalisasi, seperti faktor yang yang diuraikan di atas, faktor yang sehari-hari dialami perempuan pedesaan adalah 1) beratnya beban kerja dan panjangnya waktu kerja perempuan selain mengurusi urusan rumah tangga, perempuan sangat tinggi berkontribusi atas keuangan keluarga; 2) masih rendahnya tingkat partisipasi perempuan dari pada lakilaki pada tahapan proses dan pelaksanaan pembangunan Desa; 3) masih rendahnya peluang untuk meningkatkan kapasitas diri, misalnya masih ada sebagian masyarakat pedesaan yang beranggapan anak laki-laki lebih diutamakan. Perempuan masih terkesan di nomor duakan, lihat dikegiatan PKK, Dasa wisma, Pos yandu, kelompok pengajian, arisan dan lain-lain, kegiatan tersebut masih bergelut diseputar masak memasak, jahit menjahit, dan urusan rumah tangga.

Isu tersebut berimplikasi pada kiprah perempuan di berbagai sektor, ini terjadi di negera berkembang pada umumnya masih terjadi ketidaksetaraan gender, penelitian ${ }^{17}$ $\mathrm{dan}^{18}$ mengatakan perusahan memilih perempuan karena standar upah yang lebih rendah dari laki-laki. Sementara penelitian ${ }^{19}$ dilakukan pada perusahan jasa dan manufaktur/ritel di 87 negara berkembang, jumlah manajer puncak perempuan tinggi pada perusahan di bidang jasa dari pada di bidang manufaktur, argumen yang diberikan karena perusahan ritel tidak memerlukan keahlian teknis. Dari hasil penelitian di atas dapat diambil hal positif, bahwa perempuan dominan pada bidang jasa. Bidang jasa banyak tantangan dan permasalahan yang datang tiba-tiba, perlu inovasi dan kreatifitas yang tinggi, perempuan memiliki potensi dan memiliki kecerdasan mencari solusi serta kecerdasan bertahan dalam setiap perma salahan hidup yang dialami. Perempuan ternyata lebih ulet, lebih sabar, lebih tekun dan tetap istiqomah dalam upaya memperbaiki kualitas hidup bagi keluar ganya.

Penerapan UU Desa, yang mengalokasikan DD lebih kurang 800 juta per desa menjadi peluang bagi kaum perempuan dalam merencanakan program pembangunan dengan mengintegrasikan Instruksi Presiden Nomor 9 Tahun 2000 tentang Pengarusutamaan Gender (PUG) dalam Pembangunan Nasional. Maka tidak ada alasan bagi apartur desa untuk tidak melibatkan perempuan dalam setiap pro gram pembangunan. Perempuan dituntut untuk berpartisapasi agar pengelolaan DD, dapat bermanfaat bagi kaum perempuan khususnya dan masyarakat umumnya. Agar optimalisasi peran perempuan dalam penge Iolaan Dana Desa, perlu langka kongkrit dan komitmen bersama semua stakeholder dimulai dengan memperkuat kelembagaan kewanitaan di Desa (PKK, posyandu, dasawisma dan lai-lain) membuat jaringanjaringan individu dan kelompok, jaringan tersebut bisa informal maupun informal, jaringan ini sebagai modal sosial akan membantu setiap permasalahan yang dihadapi perempuan. Penguatan kapasitas kelembagaan kewanitaan sebagai organisasi dan meningkatkan kapasitas individu seba gai individu dengan cara belajar, belajar dan belajar. Dalam pengelolaan Dana Desa peran perempuan sangat dibutuhkan agar Dana Desa dapat dikelola sesuai dengan aspirasi perempuan, diharapkan berimplikasi terhadap kesejahteraan masyarakat dan kemandirian masyarakat desa.

\section{Modal Sosial dan Pengelolaan Dana Desa \\ odal sosial adalah seperangkat daya dalam membangun hubungan-hubu I ngan sosial, membangun jaringan,} membentuk komunitas, membangun orga nisasi, yang dapat dipergunakan untuk mengatasi masalah yang dihadapi. Modal sosial didefinisikan oleh Fukuyama sebagai serangkaian nilai dan norma informal yang dimilki bersama diantara para anggota suatu kelompok masyarakat yang memungkinkan terjadinya kerjasama diantara mereka ${ }^{6}$. Lebih lanjut Fukuyama menjelaskan ada tiga unsur utama dalam modal sosial adalah trust (kepercayaan), reciprocal (timbal balik), dan interaksi sosial. Dampak modal sosial dan kepercayaan masyarakat terhadap pengelolaan dana desa: 1) dapat mendo rong seseorang atau kelompok untuk bekerjasama dengan orang lain untuk memunculkan aktivitas ataupun tindakan bersama yang produktif; 2) menimbulkan produk dari norma-norma sosial kooperation yang sangat penting yang kemudian menunculkan modal sosial; 3) Trust bermanfaat bagi pencipta ekonomi tunggal 
karena bisa diandalkan untuk mengurangi biaya; 4 ) tercipta kesediaan seseorang untuk menempatkan kepentingan kelompok diatas kepentingan individu; 5) akan terlahir solidaritas kuat yang mampu membuat masing-masing individu bersedia mengi kuti aturan, sehingga ikut memperkuat rasa kebersamaan. Bisa saja terjadi low-trust dianggap lebih inferior dalam perilaku ekonomi kolektifnya. Jika low-trust terjadi dalam suatu masyarakat, maka campur tangan negara perlu dilakukan guna memberikan bimbingan ${ }^{6}$. Oleh karena itu, modal sosial yang kita miliki harus kita maksimalkan, karena modal sosial itu membangun koneksi, menghindari isolasi, dan dapat mempermudah pencapaian kesejahteraan masyarakat.

Paradigma baru pengelolaan ke uangan daerah melalui kebijakan otonomi daerah dan perimbangan keuangan pusat dan daerah, dimulai dengan terbitnya UU Nomor 22 Tahun 1999 Tentang Pemda dan UU Nomor 25 Tahun 1999 tentang Perimbangan Keuangan Antara Pusat dan Daerah. Terbitnya UU tersebut babak bau perubahan yang sangat mendasar me ngarah pada reformasi kelembagaan dan reformasi manajemen sektor publik dalam pengelolaan keuangan negara. Paradigma baru tersebut berupa tuntutan untuk melakukan pengelolaan keuangan daerah yang beroreintasi pada kepentingan publik. Meliputi tuntutan kepada Pemda untuk membuat laporan keuangan dan trans paransi informasi anggaran kepada masyarakat.

Selain UU di atas ada UU Nomor 6 tahun 2014 tentang Desa, menjelaskan alokasi keuangan yang diperuntukan pembangunan pedesaan, yang langsung dikelola oleh pemerintah desa berasaskan partisipasi masyarakat. Lebih detail ditegas kan dalam Peraturan Menteri dalam Negeri Nomor 37 Tahun 2007 Bab II Pasal 2 tentang Azas Pengelolaan Keuangan Desa. Keuangan desa dikelola berdasarkan azasazas transparan, akuntabel, partisipatif serta dilakukan dengan tertib dan disiplin anggaran

Dalam konteks pengelolaan DD, penerapan azas transparansi dan partisipasi tersebut, dibutuhkan modal sosial, agar timbul saling percaya antara masyarakat dengan pengelola DD, pengelolaan DD dalam hal ini diwakili oleh aparatur desa, mampu mengakomodir aspirasi masyarakat dengan cara melakukan musyawarah desa terutama mengajak kaum perempuan dalam Musrembangdes, setiap program pemba ngunan desa yang tertuang dalam APBDes, sesuai nilai dan norma serta sesuai dengan kebutuhan masyarakat. Dalam pengelolaan DD peran perempuan ditempatkan sebagai subjek bukan objek, menggunakan pende katan Gender And Development (GAD), perempuan menjadi agen perubahan de ngan menitikberatkan pada pola jaringan kesetaraan gender. Dalam pengelolaan DD, semua stakeholder penting memiliki persepsi bahwa kemitraan, kesejajaran antara perempuan dan laki-laki dengan mengu tamakan persamaan hak, kedudukan, kemampuan, peranan, imbalan kerja (upah) yang sama, kesempatan yang sama, da lam perencanaan dan pelaksanaan pembangunan di Desa.

\section{Kesimpulan}

ecara umum ketidaksetaraan gender $\longrightarrow$ masih terjadi negara-negara berkem bang, begitupun di Indonesia terutama pada masyarakat Desa. Rendahnya kiprah perempuan pada sektor pemerintahan Desa berimplikasi, rendahnya peran perempuan dalam pembanguan desa terutama pengelolaan keuangan DD. Faktor penye babnya adalah 1) kebijakan/regulasi provinsi/kabupaten belum mengintegrasikan kesetaraan gender disetiap program kerja sesuai Peraturan Pemerintah Nomor 7 Tahun 2005 bahwa sasaran pembanguan ke dua diprioritaskan kepada keadilan gender; 2) masih sebagian masyarakat memiliki persepsi memposisikan perempuan hanya pada urusan rumah tangga, sementara lakilaki lebih layak diposisikan pada sektor publik; 3) masih rendahnya kapasitas kelembagaan PKK, Posyandu, Dasawisma dan lain lain sebagai organisasi yang menaungi para perempuan dan masih rendah kapasitas individu kaum perempuan.

Rekomendasi urgent dilakukan pemberdayaan perempuan dan mening katkan kapasitas organisasi kelembagaan kewanitaan dan individu kaum perempuan ( meningkatkan pengetahuan dan keteram pilan dalam segala aspek) sebagai sumberdaya yang potensial dalam pembangunan nasional. 


\section{Daftar Pustaka}

1. Darmi T. Indonesia Dalam Menghadapi MEA Dalam Perspektif Meningkatkan Kapasitas Aparatur Desa. 2015:169

2. KemenKeu. Alokasi Dana Desa Tahun 2016 Menurut Kabupaten/Desa. 2016:1-7

3. Komisi Pemberantasan Korupsi (KPK). KPK Temukan 14 Potensi Persoalan Pengelolaan Dana Desa. http://www.kpk.go.id/id/berita/siaran-pers/2731. June 2015

4. A y u K u s uma s t u t i. Modal Sosial dan Mekanisme Adaptasi Masyarakat Pedesaan dalam Pengelolaan dan Pembangunan Infrastruktur. Masy J Sosiol. 20 Nomor 1:81-97.

5. BPS RI. Indeks Pembangunan Gender 2014. 2015.

6. Francis Fukuyama. Social Capital and Civil Society.; 2000.

7. Lockhart WH. Building Bridges and Bonds: Generating Social Capital in Secular and FaithBased Poverty-to-Work Programs. Sociol Relig. 2005;6 Nomor 1:45-60. ProQuest.

8. Lijun Song. Social Capital and Psychological Distress. J Health Soc Behav. 2010;52(4):478-492. doi:10.1177/0022146511411921.

9. Dominiak.et.al J. Social capital in the Poznań agglomeration. Bull Geogr Socio-economic Ser. 2012;18:5-14.

10. Geeke Waverijn.et.al. A prospective analysis of the effect of neighbourhood and individual social capital on changes in self-rated health of people with chronic illness. BMC Public Health. 2014;14:675. http://www.biomedcentral.com/1471-2458/14/675.

11. Otniel Pontoh. Identifikasi dan Analisis Modal Sosial dalam Rangka Pemberdayaan Masyarakat Nelayan Desa Gangga Dua Kabupaten Mihahasa Utara. J Perikan dan Kelaut Trop. 2010; $\mathrm{VI}(3)$.

12. Suwandi. PARTISIPASI MASYARAKAT DALAM PELAKSANAAN ALOKASI DANA DESA (ADD) DI KANTOR DESA SUKA DAMAI KECAMATAN MUARA BADAK KABUPATEN KUTAI KARTANEGARA. eJournal Adm Negara. 2015;3(4):1183-1194. ejournal.an.fisipunmul.ac.id.

13. I Wayan Saputra. Efektivitas Pengelolaan Alokasi Dana Desa Pada Desa Lembean Kecamatan Kintamani, Kabupaten Bangli Tahun 2009-2014. Jur Pendidik Ekon. 2016;6 Nomor 1.

14. Hariany Idris. ANALISIS PENGELOLAAN KEUANGAN ALOKASI DANA DESA DALAM PEMBERDAYAAN MASYARAKAT DESA. J Birokrat Ilmu Adm Publik. 2014;1 Nomor 2:1522.

15. Ni Kadek Darmiasih, Ni Luh Gd Erni Sulindawati NASD. ANALISIS MEKANISME PENYALURAN ALOKASI DANA DESA (ADD) PADA PEMERINTAH DESA (Studi Kasus Desa Tri Buana, Kec.Sidemen, Kab.Karangasem). e-journal S1 Ak Univ Pendidik Ganesha Jur Akunt Progr S1. 2015;1 Nomor 2.

16. BPS RI. Statistik Politik 2014. Jakarta; 2014. https://www.bps.go.id.

17. Seguino S. Gender Inequality and Economic Growth: A Cross - Country Analysis. World Dev. 2000;28(7):1211-1230. doi:10.1016/S0305-750X(00)00018-8.

18. Grotti R, Scherer S. Does gender equality increase economic inequality? Evidence from five countries. Res Soc Stratif Mobil. 2016;45:13-26. doi:10.1016/j.rssm.2016.06.001.

19. Amin M, Islam A. Are there more female managers in the retail sector? Evidence from survey data in developing countries. J Appl Econ. 2014;17(2):213-228. doi:10.1016/S15140326(14)60010-6 